\title{
DIGITALISATION OF HIGHER EDUCATION - TEACHERS AND STUDENTS EXPERIENCE
}

\author{
Marcin Fojcik $\mathbf{1}$, \& Martyna K. Fojcik ${ }^{2}$ \\ ${ }^{I}$ Department of Electrical Engineering, Western Norwegian University of Applied Sciences (Norway) \\ ${ }^{2}$ Faculty of Humanities and Education, Volda University College (Norway)
}

\begin{abstract}
In Norway, as in the rest of the world, the development is constantly moving towards more and more automatization and digitalization. Increasing the efficiency of tasks by leaving them to computers and implementing modern technology in the private and working sectors is becoming. Digitization is about using the technology to innovate, simplify and improve tasks and to offer new kind of services that are easy to use, efficient and reliable. Digitalisation in the higher education is about facilitating the use of digital tools and technological solutions to emphasize learning and to create new opportunities for learning and teaching processes.

Times are changing, and institutions in the higher education sector need to create a learning model that blends curriculum with changes in the society, receiving and adapting technology and varying expectations of the students. When studying, you want to get an education that is relevant, quality assured and provides the opportunity for a good job afterwards. One challenge for the higher education sector is to adapt new kind of learning design to modern students and technology. Lectures are undoubtedly an important part of the learning process for the students, which the school system is based on, but the lectures do not provide an automatic professional competence in an arena. To hear about something or to follow a recipe for a task is not the same as having knowledge, skills and being self-reliant. What is important that students take responsibility for their own learning, and that they are active, mentally active. To do so, students need to be motivated for learning.

We think that the solution for learning with or through digital tools have a potential for improving the efficiency and quality of teaching and research. In order to succeed in exploiting this potential, teachers should know more about how their use of digital tools affects students' learning patterns and motivation, something we would like to explore further.

This paper will be based on our previous experiences and research on what teachers and students think about using digital tools for learning. In this project we will compare teaching with or through digital tools at different institutions for higher education. We would like to find and analyse how students studying and university colleges, in different cities, with different subjects are affected by teaching with or through digital tools and how does it affect their study patterns and motivation for learning.
\end{abstract}

Keywords: Students, digital tools, higher education.

\section{Introduction}

Today's society is filled with technology and different digital tools. According to PricewaterhouseCoopers (pwc): "Many universities are developing specific digital strategies in reaction to the massive shift towards using new technology, yet lack of vision, capability or commitment to implement them effectively" (pwc, 2018, p. 3). The digitalization or the digital revolution is affecting the entire education system, from using technology to maintain information or to communicate, to introduce students to digital resources, notes or films (Thoring, Rudolph and Vogl, 2017). In this study the authors would like to research how different groups of students think about using digital tools in higher education, and to compare students views with teachers experience on using digital tools in different courses. The research question is: How can digitalisation of higher education through digital tools affect students and teachers in teaching and learning practice. 


\section{Background}

Digitalization has no standard definition in educational research, but it can be described as a process where digital tools and resources are exchanging or modifying previous options. This gives an opportunity to use different electronical solutions (e-solutions/e-learning solutions) to diverse teaching and learning (Coccoli, Guercio, Maresca and Stranganelli, 2014; Schuster, Gross, Vossen, Richert and Jeschke, 2016). This topic is relevant for today's society but many researches do not show any correlation between digital tools and greater learning outcomes (Bates, 2019, Smeets, 2005, Thoring et al, 2017). Some research comment that the digitalization in higher education is at an early stage, because despite the teachers will and use of digital tools to innovate and differentiate teaching, the are no significant changes in students learning“" (Thoring et al, 2017). While discussing what is a common learning and teaching design, and what kind of learning and teaching design education today needs Tony Bates states that: "for all other important learning activities, such as developing critical thinking, deep understanding, and application of knowledge - the kind of skills in a digital age - lectures are ineffective. Other forms of teaching and learning - such as opportunities for discussion and student activities - are necessary" (Bates, 2019, p. 87).

\section{Methods}

One of the digital tools that is use in higher education is watching lectures through video or streaming. Video can be prepared as an additional part or instead of classic lectures. There are many ways to use video in classrooms as short films, explanations, streaming, conference- or meeting systems. In this paper the authors chose to compare students and teachers experiences in using digitalisation in some ways. First: compare between one-way streaming and to-ways conference systems. Secondly: compare the use of the identical technical devices in different ways - with or without teacher.

To answer the research question proposed in this study, the authors conducted a survey with 44 students from several different subjects on HVL (Western Norwegian University of Applied Sciences). $37 \%$ of the students are students of automation, $20 \%$ of computer science (IT) and $43 \%$ are postgraduate students of Technology for Health and Nursing (THO). Similar survey was conducted in HVO (Volda University College) with 18 postgraduate students in studying advanced mathematics in teacher's education.

The students responded to the anonymous questionnaire and the survey was previously reported to the Norwegian Data Research Centre (NSD) and assessed as non-submittable.

\section{Results}

There are different ways to evaluate the results of students learning outcomes. It is possible to check the achieved grades on exams or ask students about their opinion. This paper is based on students opinions and teachers previous experience.

\subsection{Students reflections from survey}

Our results show (Figure 1) that most of the students want modern teaching methods, with digital tools, but at the same time they expect the teacher to be there - to be able to ask questions, and to help students, for example by motivating or supervising them. In total, $78 \%$ of students wanted to use digital tools to support learning in combination with traditional teaching or on their own, but in the same time $60 \%$ of students would have a teacher physically present in the lecture, see Figure 2.

Figure 1. Lecture form according to students needs.

\begin{tabular}{|l|l|l|l|}
\hline HVL - Automation & HVL - IT line & HVL - THO & HVO - Math \\
\hline & & & \\
\hline
\end{tabular}


Figure 2. Access to the teacher according to the students.

\begin{tabular}{|l|l|l|l|}
\hline HVL - Automation & HVL - IT line & HVL - THO & HVO - Math \\
\hline & & & \\
& & & \\
\hline
\end{tabular}

Table 1. Different types of needs that students like in lectures.

\begin{tabular}{|l|c|c|c|}
\hline \multicolumn{1}{|c|}{ Course } & $\begin{array}{c}\text { Lectures adapted for the } \\
\text { students [\%] }\end{array}$ & $\begin{array}{c}\text { Possibility to ask } \\
\text { questions [\%] }\end{array}$ & $\begin{array}{c}\text { Engaging, varying } \\
\text { lectures [\%] }\end{array}$ \\
\hline HVL - Automation & 53 & 71 & 59 \\
\hline HVL - IT & 89 & 67 & 67 \\
\hline HVL - THO & 69 & 38 & 44 \\
\hline HVO - Math & 89 & 28 & 67 \\
\hline
\end{tabular}

This result show that students are generally satisfied when the teacher is present, the lectures are adapted for the students and the teacher is varying the methods of learning during lectures. In Figure 1, there is a similarity in the two postgraduate courses. Even though one course is about medicine and the other about mathematics, the students express a wish to combine both digital and traditional form of lectures. That meant they wish to both meet the teacher face to face, as well as using digital tools like computers, calculators and video. In figure 2, the similarity is between IT and Math. Both courses have a lot of streaming and are capable to learn much on their own. That may be a reason why the students form those courses want engaging and varying lectures, like showed in table 1 . Another result in the table 1 is that the two postgraduate courses does not express the desire to ask questions during lectures. It looks like they are satisfied with what they hear through streaming, or that they have enough experience in studying that they know how to learn on their own.

\subsection{Teachers reflections}

The authors experience shows that not always the student's opinions and expectations are matching the teacher's opinions. In THO subject there are at least 6 teachers ( 2 in each campus) on all lectures. They are available on the lectures, breaks and during exercises. There is a possibility (that is often used by students) to ask detailed question or get feedback. As results of all this effort, some students from THO think that the teacher is not necessary to be present for their learning, while students that does not have local teacher present during streaming or video lessons are more appreciate if the teacher is present, figure 1. On other courses students expressed the need to have a teacher available in best case scenario in classroom, if not on campus, at least to have the possibility to contact the teacher online or on the phone. The authors have observed many times than learning process is much more effective when teacher is a part of process and can supervise and support the students.

In the authors experience there are some students with attitudes like: "we want to show that we are able to do whole project alone - without teachers help or supervising", and often their results are acceptable, but with supervising and help from an experienced teacher, the same students might have achieved better grades. A similar situation was observed in Volda in a fully online course that is not taking directly part in this study, but it has given the authors many experienced. It is a digital course where all lectures are published through an online learning platform, through video and digital tools - without present teacher. There is a possibility to contact the teacher online, but it was not obligatory, and the students are choosing themselves if they want or need help or they can figure things out on their own. In this course there were few of the students which commented after a semester that they did not perform as well as they could, because the topic for final project were too difficult, and they had a hard time doing it without any help, yet they did not ask for any.

Another interesting experience of the authors is a case where to courses had identical equipment, but the situation and the experience of students were very different. One course had a local teacher while streaming from another campus, and the other had only a teacher through streaming. In this study the participants from the course Technology in Medicine and Nursing THO had mostly positive response on the quality of the lectures. The course was about using different aspect of technology in medical/nursing practice. Both teacher from nursing and technology were present in every classroom on three campuses as 
a control and help through additional skype connection (invisible for students). The teachers cooperate both before, during and after the lectures to control the entire process of streaming. There were no negative remarks from students about teaching process, and there were a group of students that commented that local teacher was not necessary.

After the study finished, the authors contacted another course on HVL for postgraduates in nursing that was using the same equipment. Clinical Nursing is also a course possible on three campuses, but it only has one teacher. So, the teacher has lecture on one campus and streams the same lecture to the remaining two campuses. There was no local teacher, only one a chosen student to help with control all the devices. Generally, the students were satisfied. However, there were many technical and organizational challenges like: control and quality of microphones, identification of questions (who ask, who should take control over camera and microphone), synchronisation. The students did not want to interrupt the lecture for the other campuses, so there was not easy to stop the lecture to ask the teacher some questions or confirm that the other campuses have possibility to see and hear the teacher and read the teachers notes on the board. The students briefly commented that there were some misunderstandings, leap in incoming sound and/or video, or a camera that did not show teachers notes, but it was difficult to contact the other campuses, and some students found it a little frustrating. This experience shows that the same classroom and the same tools can be used the same way but work totally different.

\section{Discussion and conclusion}

Most of the students from selected subjects taught in the HVL and HVO participated in the survey, but both schools are rather small, so the survey is not fully representative in quantitative terms. The results can only show the trend in both places.

Students who have been streaming since the beginning of their studies are used this way of having a lecture. They do not know that it is possible otherwise. Students who start in the "classical/traditional" way are not used to working completely independently, and sometimes have a hard time trying. Students evaluation of the system depends on the form of lectures they have now or previously had. In order to achieve greater accuracy, it would be necessary to have a control group with the same technical means. This has been discussed for two subjects, Clinical Nursing and Technology in Medicine and Nursing THO. The students without a teacher were generally satisfied but had a lot of comments about the equipment and the possibility of active participation: asking questions was quite complicated and embarrassing for some students. It was not possible to ask questions during a break or to consult the teacher personally. This may be because the students selected to coordinate did not have organizational or pedagogical experience and did not meet the challenge. According to Schuster et al, (2016) the digitalization of education should give the students an opportunity to be more active, and when some of the teaching and learning is based in a digital environment, the communication skills are very important to avoid misconceptions and problems.

Students with the same equipment, but in the course with many teachers did not make any comments about the technical or pedagogical problems. Almost always there was a local discussion between students and teachers after lectures or during practice and breaks. It turned out that everything was so well prepared that quarter of the students in this course were the only ones in the survey who wrote that the teacher was not needed. Is that good?

Perhaps it could be more effective not to replace the teacher with a video or streaming, but to create a full system of two-way contact. Such a system, apart from video, would have the possibility for students to write questions - so as not to interfere with an ongoing lecture for several campuses. The teacher could answer at the earliest opportunity so as not to interrupt the presentation. In addition, the (optional) system would automatically show the student asking the question so that everyone could hear/see what is happening. Situations where the teacher in the classroom is the only one who sees the question and then answers it are a disruption to the students on site. Unfortunately, so far none of the conference systems have such possibilities and using several different systems at the same time requires much more skills and practice.

The situation is similar for all types of students. Regardless of the form of teaching (classical, video, streaming, on or off campus) not all of the students use their abilities in lectures. This can be seen in presentations of final projects, tests or exams. Students are not always able to use the help of a teacher (for example in the HVL for projects, or for technical reasons in the HVO - lack of a system to facilitate contact). This assistance manifests itself in for example: explaining, repeating, advising, correcting, and much more. Without it, students have much more pressure on themselves not only to understand the subject, but also to understand the assignment, field of work, experience and practice of the subjects. In the authors experience such students are writing not exactly on the subject core or not answering questions but modifying them according to their needs and point of view. This applies to HVL and HVO. 
For remote students the only (optional) way to contact them is by email, skype or phone. There are no mandatory contact options and some students chooses not to contact the teachers at all, even when they find the subject material hard to understand. This, in some cases, makes the learning process difficult.

In Norway there are big discussions on how teacher's professional digital competence is affecting students (Engen, Giæver and Mifsud, 2015; Johannesen, Øgrim and Givær, 2014), but this study pointed more of the technological aspects of digitalization. This would be interesting to research in further studies.

To sum up, digital systems largely cover the constellation but there is no full system available now. None of them have all the necessary features both according to this study, the authors experience and literature (Coccoli et al, 2014; Thoring et al, 2017).

\section{References}

Bates, A.W. (2019). Teaching in a digital age. Guidelines for designing teaching and learning. 2. Edition. Retrieved from https://teachonline.ca/teaching-in-a-digital-age/teaching-in-a-digitalage-second-edition

Coccoli, M., Guercio, A., Maresca, P., and Stanganelli, L. (2014). Smarter universities: A vision for the fast changing digital era. In Journal of Visual Languages \& Computing, 25(6), 1003-1011.

Engen, B. K., Giæver, T. H., and Mifsud, L. (2015). Guidelines and regulations for teaching digital competence in schools and teacher education: a weak link? In Nordic Journal of Digital Literacy, 10(Jubileumsnummer), 172-186.

Fojcik, M., Fojcik, M. K., Hegland, P. A., Kyte, L., Midtbø, T. G., Pollen, B., Sande, J. And Sande, O. (in rewiev). Praktisk digitalisering av høgskuleundervisning erfaringar frå forelesarar og studentar. Fjordantologi 2020.

Johannesen, M., Øgrim, L., and Giæver, T. H. (2014). Notion in motion: Teachers' digital competence. In Nordic Journal of Digital Literacy, 9(04), 300-312.

PricewaterhouseCoopers (2018). The 2018 digital university. Staying relevant in the digital age. Retrieved from https:/www.pwc.co.uk/assets/pdf/the-2018-digital-university-staying-relevant-inthe-digital-age.pdf

Raschke, C. A. (2003). The digital revolution and the coming of the postmodern university. Routledge.

Schuster, K., Gross, K., Vossen, R., Richert, A., and Jeschke, S. (2016). Preparing for industry 4.0 - Collaborative virtual learning environments in engineering education. In Engineering Education 4.0, 477-487. Springer, Cham.

Selwyn, N. (2014). Digital technology and the contemporary university: Degrees of digitization. Routledge.

Smeets, E. (2005). Does ICT contribute to powerful learning environments in primary education? In Computers \& Education, 44(3), 343-355.

Thoring, A., Rudolph, D., and Vogl, R. (2017). Digitalization of higher education from a student's point of view. In EUNIS 2017-Shaping the Digital Future of Universities, 279-288. 